\title{
TRANSMIGRATION OF MANDIBULAR SECOND PREMOLAR IN A PATIENT WITH CLEFT LIP AND PALATE - CASE REPORT
}

\author{
Daniel Berretta Moreira ALVES' ${ }^{1}$ Ésio Fortaleza Nascimento Chaves PEDROSAํㅗㄴ Jesus Carlos ANDREO², \\ Izabel Maria Marchi de CARVALHO ${ }^{3}$, Antonio de Castro RODRIGUES ${ }^{4}$
}

1- DDS, Dental Radiologist.

2- PhD, Associate Professor, Department of Human Anatomy, Bauru School of Dentistry, Bauru, SP, Brazil.

3- DDS, PhD, Dental practitioner, Hospital for Rehabilitation of Craniofacial Anomalies, University of São Paulo (HRAC/USP); Professor, Dental School, University of Sagrado Coração, Bauru, SP, Brazil.

4- BSc, PhD, AssociateProfessor, Department of Human Anatomy, Bauru School of Dentistry, Bauru, SP, Brazil.

Corresponding address: Prof. Dr. Jesus Carlos Andreo - Faculdade de Odontologia de Bauru - Universidade de São Paulo - Al. Dr. Octávio Pinheiro Brisolla 9-75 - Vila Universitária - 17012-901 Bauru, SP, Brasil - Phone: +55-14-3235-8226 - email: jcandreo@usp.br

Received: September 5, 2007 - Modification: November 22, 2007 - Accepted: April 15, 2008

\begin{abstract}
$D$

isturbances involving abnormalities in tooth eruption are named ectopia. Transmigration is the name assigned to ectopia in the presence of teeth in areas distant from the alveolar process. Initial angulation of the tooth bud of the second premolar and premature loss of permanent mandibular 1st molars can influence the distal migration of the second premolar. Some studies have observed that ectopic teeth can be found in a variety of places around the oral cavity and also in other areas of the human body. There are records of teeth in the maxillary sinus, mandibular condyle, coronoid process, mandibular angle, orbit, palate, mentum and also the skin. The prevalence of tooth abnormalities is higher in children with cleft lip and palate compared to children without clefts. This paper presents a case report of migration of the mandibular left second premolar in a patient attending the Hospital for Rehabilitation of Craniofacial Anomalies of the University of São Paulo (HRAC/USP), Brazil. Migration of the mandibular left 2nd premolar was confirmed by 8 panoramic and 1 periapical radiographs obtained during patient's treatment between 1978 and 2002, which were available in the files of the Department of Dental Radiology of HRAC/USP. It can be assumed that distal migration of the mandibular left 2nd premolar is not associated with presence of cleft lip and palate; observation of these two events in a same patient is rare, since no similar reported cases were found in the literature.
\end{abstract}

Key words: Mandible. Bicuspid.

\section{INTRODUCTION AND LITERATURE OVERVIEW}

The incidence of tooth abnormalities in children with cleft lip and palate is higher than that in children without clefts $^{3,5,16}$. Tooth abnormalities reported in the literature are related to the number, size, shape and eruption of teeth ${ }^{3,8,16}$.

Disturbances involving anomalies in tooth eruption are called ectopia and may be observed in several regions around the oral cavity, as well as in other areas of the human body. There are reports of teeth in the maxillary sinus, mandibular condyle, coronoid process, orbit, palate, mentum and skin. Teeth have also been found in unusual sites, including the ovaries, testicles, anterior mediastinum, retroperitoneal,

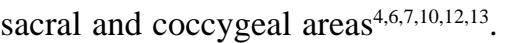

Transmigration or migration is the term assigned to ectopia when teeth are present in areas distant from the alveolar process ${ }^{2}$.

The term unerupted tooth is used to designate a tooth that presented failure in eruption as a result of malpositioning, delayed eruption or impaction ${ }^{23}$. The term dental migration may indicate the movement of an unerupted tooth to an area far from its regular place of development. This denomination does not refer to displacement of a totally or partially erupted tooth to an abnormal position in the dental arch. According to Peck (1998), dental migration refers to the horizontal movement of unerupted teeth and occurs only in the mandible. The unerupted teeth most frequently presenting migration are the premolars ${ }^{15,22}$, with predominance of females over males ${ }^{11,22}$, canines ${ }^{15,22}$, and mandibular 3rd molars ${ }^{22}$. Intraosseous migration of premolars is less frequently found in the literature than migration of the canine.

The first description of migration of mandibular 1st molar 
was published by Shields ${ }^{19}$ in the early 1900's. Since then, other cases have been reported ${ }^{3,8,9,10,13,14,16,17,21,24}$. Later reports presented cases of migration of the mandibular 2nd premolars due to early loss of the permanent mandibular 1st molars ${ }^{10,11,15,18,20,22}$.

Matteson, et al. ${ }^{11}$, (1982) reported the importance of the knowledge of the mechanism of tooth eruption to understand ectopic migrations, which aids in the diagnosis, prevention and treatment of these occurrences. Sutton ${ }^{22}$ (1968) suggested that the initial angulation of the tooth and frequent loss of primary mandibular 1st molars are important for distal migration of mandibular premolars. However, Peck ${ }^{15}$ (1998) suggested that canine migration may have a genetic cause based on observation of cases of bilateral migration, while migration of premolars is either casual or idiopathic, rather than genetic.

Distal migration is not yet completely known, since the teeth tend to present mesial movement due to masticatory efforts. The chance of intraosseous migration of the 2nd premolar is significantly increased in case of early loss of the permanent 1st molar, that is, before eruption of the $2 \mathrm{nd}$ premolar. After loss of the permanent mandibular 1st molar, the possibility of distal migration of the mandibular 2nd premolar ranges from 5 to $10 \%{ }^{11}$.

Mandibular 2nd premolars presenting severe migration from their usual site to the region mesial to the permanent mandibular 2nd molar, where it then erupts normally, are named paramolar-wanderung ${ }^{1}$.

Radiographic follow-up of transmigration can be performed. However, decision on surgical removal depends on the symptoms reported by the patient, the site where the tooth is found, and presence or not of associated pathologies. Surgical removal can be performed via intraoral or extraoral access with care to avoid damage to the inferior alveolar nerve or jaw fracture ${ }^{9,6,12}$. Even though the occurrence of tooth abnormalities is higher in permanent teeth, they have also been reported in the primary dentition, more frequently in children with cleft lip and palate ${ }^{3,16,5}$.

No reported case of migration of mandibular teeth in patients with cleft lip and palate was found in the literature. This paper presents a case report of migration of the mandibular left 2nd premolar in a patient attending the

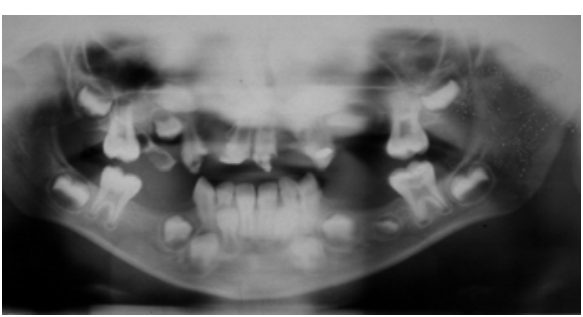

FIGURE 1- Patient at the age of 6

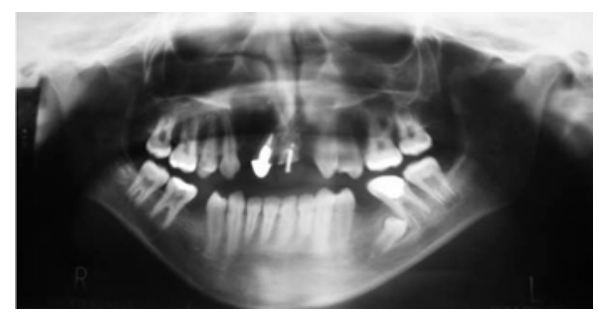

FIGURE 4- Mandibular left 2nd premolar presenting crown impaction against the mesial root of the mandibular left 1st molar at the age of 12

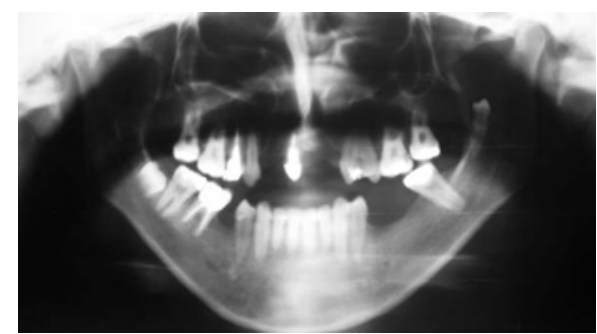

FIGURE 7- Patient at the age of 17 : mandibular left 2nd premolar located in the mandibular notch area

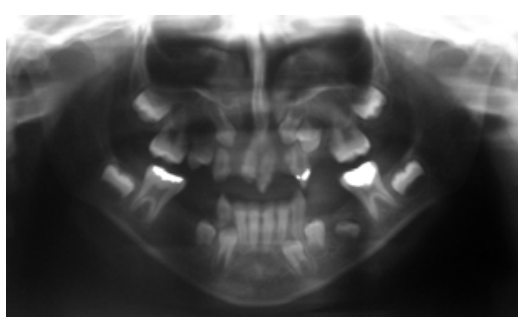

FIGURE 2- Patient at the age of 8

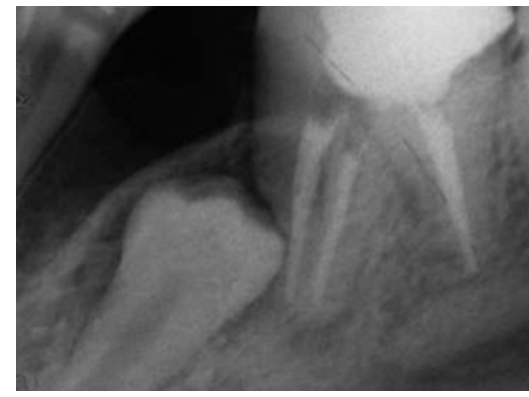

FIGURE 5- Extraction of the mandibular left 1st molar due to resorption of the mesial root at the age of 15

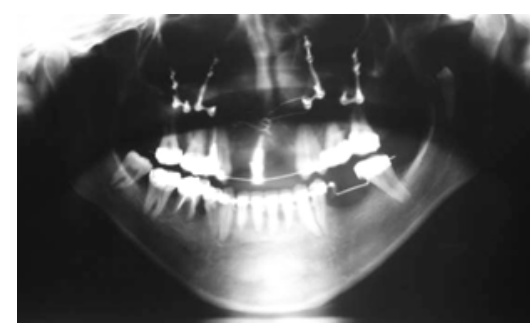

FIGURE 8- Patient at the age of 23: mandibular left 2nd premolar located in the mandibular notch

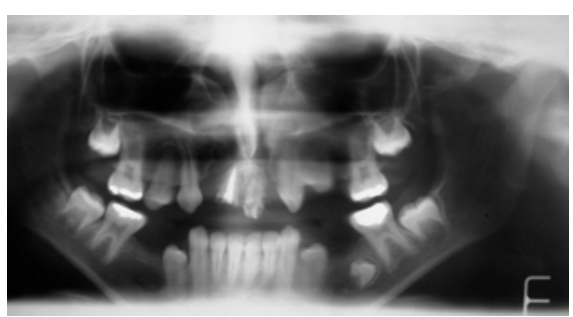

FIGURE 3- Patient at the age of 11

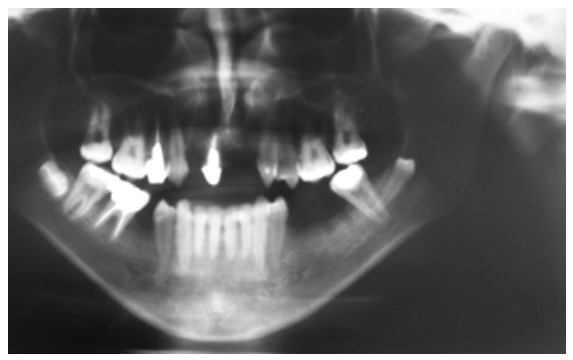

FIGURE 6- Two months after extraction of the mandibular left 1 st molar at the age of 15

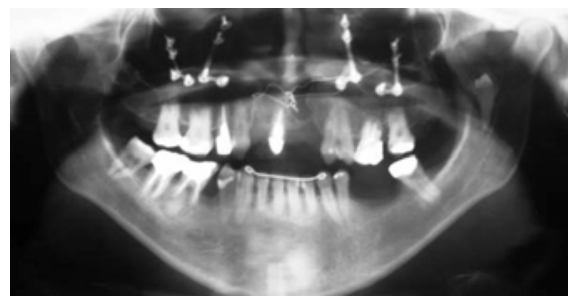

FIGURE 9- Patient at the age of 30 : mandibular left 2nd premolar located in mandibular notch area, without significant alteration 
Hospital for Rehabilitation of Craniofacial Anomalies of the University of São Paulo (HRAC/USP), Brazil.

\section{CASE REPORT}

The patient M. C. F. A., a 4-year-year-old female child with bilateral complete cleft lip and palate, first attended the Hospital for Rehabilitation of Craniofacial Anomalies of the University of São Paulo (HRAC/USP) in 1976 for clinical and surgical treatment. The first panoramic radiograph was taken when the patient was 6 years old. It was observed that the patient presented normal aspect of the tooth buds of maxillary right and left 1st premolars, mandibular left 1st and 2nd premolars, and mandibular right 1st premolar. The maxillary right and left 2nd premolars and mandibular right 2nd premolars were congenitally absent (Figure 1).

A new radiograph was taken at the age of 8 , which revealed abnormal angulation of the tooth bud of the mandibular left 2nd premolar, whereas the other teeth presented normal eruption pathway (Figure 2). When the patient was 11 years old, the tooth bud of the mandibular left 2nd premolar presented an horizontal position in relation to the midsagittal plane. The other teeth were erupted, except for the maxillary and mandibular right and left 2nd molars, which were in the course of eruption (Figure 3). At the age of 12, the tooth bud of the mandibular left 2nd premolar was positioned ectopically and had its crown impacted against the mesial root of the mandibular left 1st molar (Figure 4). Three years later, a periapical radiograph of the mandibular left 1st molar was obtained and extraction of the mandibular left 1st molar was planned (Figure 5). Surprisingly, only 2 months after extraction, the mandibular left 2nd premolar presented distal migration, still in a horizontal position in relation to the midsagittal plane, reaching the area of the mandibular left 3rd molar (Figure 6).

Two-year radiographic follow-up revealed that the mandibular left 2nd premolar was migrating to the mandibular ramus, without any symptomatology. The root apices were positioned in the retromolar area and the crown was located in the mandibular ramus (Figure 7). A panoramic radiograph taken at the age of 23 (Figure 8) showed that the mandibular left 2nd premolar was positioned in the mandibular notch area. The last radiograph was taken when the patient was 30 years old (Figure 9). No significant alteration in the position of the mandibular left 2nd premolar was observed.

\section{DISCUSSION}

The prevalence of intraosseous migration of premolars is low compared to other teeth, such as canines ${ }^{15}$. No reports in patients with cleft lip and palate are found in the literature.

This case report shares some characteristics with reports in the literature. In this case, when the patient was 8 years old, the tooth bud of the mandibular left 2nd premolar presented an abnormal angulation. There was also early loss of the mandibular left 1 st molar at the age of 15, which allowed distal migration of the mandibular left 2nd premolar. These events agree with those reported by Sutton ${ }^{22}$ (1968), Matteson, et al. ${ }^{11}$, (1982), Loh and Ho ${ }^{10}$ (1986), Jasmin ${ }^{7}$ (1989), Spyropoulos ${ }^{20}$ (1990), Peck ${ }^{15}$ (1998), and Shapira and Kuftinec $^{18}$ (2003). It may be inferred that the association of these two factors was determinant for distal migration of the mandibular 2nd premolar. Thus, if early diagnosis of this situation is established, the dentist may initiate the treatment before the tooth reaches a more difficult access.

In the present case, the ectopic mandibular left 2nd premolar moved to the mandibular notch, differently from the cases reported by Loh and $\mathrm{Ho}^{10}$ (1986) and InfanteCossio, et al., ${ }^{6}$ (2000), who reported dental migration to the mandibular angle; Orton and McDonald ${ }^{13}$ (1986), Jasmin, et al. ${ }^{7}$ (1989) and Okada, et al. ${ }^{12}$ (2002), who described migration to the coronoid process; Loh and $\mathrm{Ho}^{10}$ (1986), who reported migration to the ascending mandibular ramus; and Okada, et al. ${ }^{12}$ (2002), who described migration to the mandibular condyle.

Treatment for this type of anomaly varies according to the position and conditions presented by this tooth, as well as the presence of any discomfort to the patient. In the present case, it was decided not to extract the mandibular left 2nd premolar, since it did not cause discomfort to the patient or any evidence of alteration, as reported by InfanteCossio and Hernandez-Guisado, Gutierrez-Perez ${ }^{6}$ (2000) and Okada, et al. ${ }^{12}$ (2002). However, Lehman ${ }^{9}$ (1987) recommended the extraction of ectopic teeth with evidence of cyst associated with the tooth crown.

\section{CONCLUSIONS}

It may be concluded that intraosseous distal migration of the mandibular left 2nd premolar associated with cleft lip and palate is a rare condition, since no previous reports were found in the literature. However, the present case demonstrates that it occurred in a similar manner as in individuals without clefts. The presence of intraosseous distal migration seems not to be directly related with the presence of cleft lip and palate.

\section{REFERENCES}

1- Abo K. (1942) apud Matteson S R, Kantor M L, Profit W R. Extreme distal migration of the mandibular second bicuspid. A variant of eruption. Angle Orthod. 1982;52(1):11-8.

2- Alvares LC, Tavano O. Anomalias dentárias e do complexo maxilomandibular. In: Alvares LC, Tavano O. Curso de radiologia em odontologia. São Paulo: Ed. Santos; 1998. p.190-205.

3- Boehn A. Dental anomalies in harelip and cleft palate. Acta Odontol Scand. 1963;21:1-109.

4- Gupta YK, Shah N. Intranasal tooth as a complication of cleft lip and alveolus in a four year old child: a case report and literature review. Int J Paediatr Dent. 2001;11(3):221-4. 
5- Helióvaara A, Ranta R, Rautio J. Dental abnormalities in permanent dentition in children with submucous cleft palate. Acta Odontol Scand. 2004;62(3):129-31.

6- Infante-Cossio P, Hernandez-Guisado JM, Gutierrez-Perez JL. Removal of a premolar with extreme distal migration by sagittal osteotomy of the mandibular ramus: report of case. J Oral Maxillofac Surg. 2005;8(5):575-7.

7- Jasmin JR, Jonesco-Benaich N, Terestri P, Giudicelli J. Migration of an impacted mandibular second molar. Oral Surg Oral Med Oral Pathol. 1989;67(4):478-9.

8- Jordan RE, Kraus BS, Neptune CM. Dental abnormalities associated with cleft-lip and/or palate. Cleft Palate J. 1966;3:22-55.

9- Lehman RA. A deviate eruption pattern. Am J Orthod Dentofacial Orthop. 1987;91(5):427-8.

10- Loh HS, Ho KH. Unerupted and ectopic mandibular premolars. Oral Surg Oral Med Oral Pathol. 1986;62(3):358.

11- Matteson SR, Kantor ML, Proffit WR. Extreme distal migration of the mandibular second bicuspid. A variant of eruption. Angle Orthod. 1982;52(1):11-8

12- Okada H, Miyake S, Toyama K, Yamamoto H. Intraosseous tooth migration of impacted mandibular premolar: computed tomography observation of 2 cases of migration into the mandibular neck and the coronoid process. J Oral Maxillofac Surg. 2002;60(6):6869 .

13- Orton HS, Mcdonald F. The eruptive potential of teeth: a case report of a wandering lower second premolar. Eur J Orthod. $1986 ; 8(4): 242-6$

14- Parker WS. Transposed premolars, canines, and lateral incisors. Am J Orthod Dentofacial Orthop. 1990;97(5):431-48.

15- Peck S. On the phenomenon of intraosseous migration of nonerupting teeth. Am J Orthod Dentofacial Orthop. 1998;113(5):515-7.

16- Ranta R, Stegars T, Rintala AE. Correlations of hypodontia in children with isolated cleft palate. Cleft Palate J. 1983;20(2):163-5.

17- Shapira Y, Borell G, Kuftinec MM, Stom D, Nahliele O. Bringing impacted mandibular second premolars into occlusion. J Am Dent Assoc. 1996;127(7):1075-8.

18- Shapira Y, Kuftinec MM. Intrabony migration of impacted teeth. Angle Orthod. 2003;73(6):738-44.

19- Shields NT. (1908) apud Sutton PR. Migrating nonerupted mandibular premolars :a case of migration into the coronoid process. Oral Surg Oral Med Oral Pathol. 1968;25(1):87-98.

20- Spyropoulos ND. Orientation and eruptive patterns of the mandibular second premolar. Oral Surg Oral Med Oral Pathol. 1990;69(5):642-6.

21- Steelman R, Tinkler D, Kerr V, Jordan C. Ectopic developing mandibular premolar. Oral Surg Oral Med Oral Pathol. 1986;62(6):738.

22- Sutton PR. Migrating nonerupted mandibular premolars :a case of migration into the coronoid process. Oral Surg Oral Med Oral Pathol. 1968;25(1):87-98.

23- Thoma KH, Goldman HM. Oral Pathology. St. Louis: Mosby; 1960 .

24- Weber AD. A longitudinal analysis of premolar enucleation. Am J Orthod. 1969;56(4):394-402. 